\title{
Influence of Compaction Level on the Water-Heat-Vapor Characteristics of Unsaturated Coarse-Grained Fillings Exposed to Freezing and Thawing
}

\author{
Yuzhi Zhang $\mathbb{D}^{1,2}$ An Wen ${ }^{10},{ }^{1,3}$ Weigang Zhao, ${ }^{1,2}$ Xiaojie Liang, ${ }^{4}$ and Pei Li ${ }^{4}$ \\ ${ }^{1}$ Structural Health Monitoring and Control Key Laboratory of Hebei Province, Shijiazhuang Tiedao University, \\ Shijiazhuang, China \\ ${ }^{2}$ State Key Laboratory of Mechanical Behavior and System Safety of Traffic Engineering Structures, \\ Shijiazhuang Tiedao University, Shijiazhuang 050043, China \\ ${ }^{3}$ Power China Railway Construction Co., Ltd., Beijing, China \\ ${ }^{4}$ School of Civil Engineering, Shijiazhuang Tiedao University, Shijiazhuang, China
}

Correspondence should be addressed to Yuzhi Zhang; zhangyuzhi@stdu.edu.cn and An Wen; wenan_soar@163.com

Received 8 October 2019; Revised 15 April 2020; Accepted 26 August 2020; Published 6 October 2020

Academic Editor: Robert Černý

Copyright ( 92020 Yuzhi Zhang et al. This is an open access article distributed under the Creative Commons Attribution License, which permits unrestricted use, distribution, and reproduction in any medium, provided the original work is properly cited.

Compaction level is an important control index to guarantee subgrade stability. Under freezing-thawing cycles, water-heat-vapor characteristics due to different compaction levels of unsaturated coarse-grained fillings of high-speed railway (HSR) subgrade are key factors in understanding the mechanism of freezing-thawing deformations. Experiments have been performed to study the characteristics of water-heat-vapor of coarse-grained fillings with different compaction levels exposed to freezing and thawing. Fluorescein was used to trace the variations of liquid water in external moisture supply. Test results indicated that compaction level affected the water-heat-vapor characteristics of coarse-grained fillings to some extent. The increase of compaction level increased frost penetration and freezing rate; however, initial water replenishment time delayed during freezing process; liquid water migration height and external liquid migration increased, but total moisture migration, the amount of vapor migration, and vapor of the soil sample moving up to the top pedestal simultaneously reduced. Repeated freezing-thawing cycles improve the compaction of coarse-grained fillings. Variation of the amount of moisture caused by the increase of compaction level may decrease the frost heaving of coarse-grained fillings. Therefore, proper selection and uniformity of compaction level is of critical importance in HSR engineering.

\section{Introduction}

Soil compaction is one of the most commonly used methods to ensure the durability and stability of subgrades and foundations in transportation engineering to improve the strength and bearing capacity. The development of road engineering and technical standardizations such as the intelligentization of compaction machinery, California bearing ratio (CBR), and Proctor compaction curves have made soil compaction operations much more convenient than they were before [1]. However, the performance variations of compacted soils under the coupling effects of external loads and engineering practical environments are extremely complicated. In 1928-1929, a study in Canada showed that the primary reason of road damages was poor bearing capacity induced by nonuniform compaction of subgrade soil [2]. Since the elastic moduli of compacted soil layers cannot be directly measured, even with intelligent compaction technology, it is difficult to ensure the uniformity of roadbed compaction levels [3].

After compaction, subgrade soil is basically in unsaturated state and is subjected to multiple thermal-mechanical coupling effects induced by environment and external loads during operation. Equilibrium suction is affected by several factors such as surrounding soil layers, groundwater level, local climate, water content, and soil density that change 
dynamically in dry-wet cycles [1]; therefore, the performance of subgrade soils can be gradually deteriorated affecting traffic safety and creating economic losses [4]. The moisture of subgrade base fillings is highly affected by seasonal factors such as rainfall, freezing-thawing, etc. Small changes in water content usually create considerable changes in saturation state affecting the service life of roadbeds. Providing accurate descriptions for these changes requires complicated constitutive models and numerical calculations $[1,5,6]$. The moisture change caused by water migration during the freezing and thawing leads to the rearrangement of soil structure and, therefore, changes its hydraulic, thermophysical, and mechanical properties [7-9]. Currently, research on unsaturated soils is mainly focused on deformation and mechanical characteristics due to water changes and liquid water-vapor transformations at abovezero temperatures [10-16]; however, the migration and phase of vapor under seasonal freezing-thawing cycles have rarely been investigated. In fact, water in unsaturated soils can exist in the forms of liquid, vapor, and porous ice. When pores are connected, vapor can migrate. Due to the high volume of pores in compacted coarse-grained fillings which are widely used in subgrade engineering, the migration and phase transition of vapor cannot be neglected under freezing-thawing cycles. Water-heat-vapor effects due to different compaction levels under freezing-thawing cycles in unsaturated fillings should also be investigated.

Recently, the number of problems caused by unsaturated fillings under freezing-thawing conditions has increased with the construction of transportation infrastructures in cold regions of China [17-19], which would cause diseases of reinforced concrete structures in high-speed railway (HSR) ballastless tracks [20]. To understand the mechanism of freezing damage in cold areas, researchers have performed a series of experiments and theoretical studies on the mechanism of water change at below-zero temperatures in unsaturated soils. These experimental results have indicated the necessity of studying the prevalence of moisture accumulation under impervious covers and vapor migration under unidirectional freezing conditions $[19,21-25]$. To better understand the water-heat-vapor characteristics of coarse-grained fillings commonly used in the base course of HSR subgrades, Zhang et al. $[26,27]$ performed experiments to quantitatively study the influences towards the proportion of vapor migration in the mixed migration of liquid water and vapor under different oneway freezing modes in the coarse-grained fillings with different water contents. Their results indicated that vapor occupied a large proportion in migration; however, the influence of compaction level on water-heat-vapor characteristics under the effect of freezing-thawing cycles has not yet been studied.

Under the influences of seasonal freezing-thawing cycles, high-speed trains, complicated engineering environments, and largely dispersed coarse-grained soils, it is difficult to guarantee the compaction uniformity of subgrade fillings. In this paper, we used step freezing mode to simulate slow cooling winters. The influence of different compaction levels on liquid water-vapor mixed migration characteristics, temperature field, and final water content of HSR coarsegrained fillings during three freezing and two thawing processes were studied. Moreover, fluorescein was used to trace liquid water to better understand the influence of liquid water migration on the mixed migration of liquid watervapor, to further understand the mechanism of liquid watervapor migration in HSR unsaturated coarse-grained fillings in cold regions, and to provide a theoretical basis to explain its deformation and mechanical properties.

\section{Experiment Plans}

2.1. Instruments. As shown in Figure 1, liquid water-vapor migration test device was used which mainly composes of a high- and low-temperature test chamber, a sample cylinder, an ultraviolet radiation, an industrial camera, a temperature control system, sensors, and a data acquisition system. Sample cylinder had $20 \mathrm{~cm}$ height and $10 \mathrm{~cm}$ diameter, external Mariotte bottle was connected for soil sample water replenishment, and water supply and discharge amounts were read from Mariotte bottle scale. Sample tube was reserved for temperature sensor hole, which was slightly larger than the used temperature sensor (Figure 1). A high-resolution industrial camera was used to automatically capture the images of sample tube under a UV lamp. The temperatures of top and bottom cooling pedestals were controlled by freezing liquid in circulation loop. Temperature control range was $-30^{\circ} \mathrm{C} \sim+30^{\circ} \mathrm{C}$ with the precision of $0.1^{\circ} \mathrm{C}$. Top cooling pedestal was separated from the sample by a plastic film and was sealed to isolate upper vapor. At the constant temperature of base pedestal, liquid water at the bottom of the device is evaporated and migrated to the inside of the sample in a mixed liquid water-vapor mode; the water lost from the bottom water bath was replenished by Mariotte bottle in real time. STT-R platinum resistance temperature sensors with the accuracy of $0.1^{\circ} \mathrm{C}$ in the measurement range of -200 to $+100^{\circ} \mathrm{C}$ were used. A total of 8 temperature sensors were used at the top and bottom of soil samples at intervals of $30 \mathrm{~mm}$.

Researchers have studied the distribution of unfrozen water in soils using fluorescein tracers $[28,29]$. They have found that fluorescein tracer could be incorporated into water and then added to soil samples. It was found that the solute was not taken away by the evaporation of water. As shown in Figure 2, fluorescein solution was mixed with soil in a cup covered with a glass plate. Then, the bottom of the cup was heated and water evaporated; then, the glass plate was placed on a white paper to observe the condensed vapor on it. Since no color was found, fluorescein tracer could be used to observe the migration of liquid water in soils by the Mariotte bottle water with fluorescein.

2.2. Experimental Scheme. Coarse-grained soils (CGS) investigated in this study were collected from the project site in Harbin-Qiqihar HSR line. The physical properties of the collected samples are listed in Table 1. As shown in Table 1, the freezing temperature of the soil was obtained from the measurement of soil freezing process by a device developed by us in the laboratory [30]. The particle size distribution of CGS retrieved from the field is shown in Figure 3 , where $d_{10}, d_{30}$, and $d_{60}$ are $0.43,3.00$, and 7.50 , respectively. According to the 


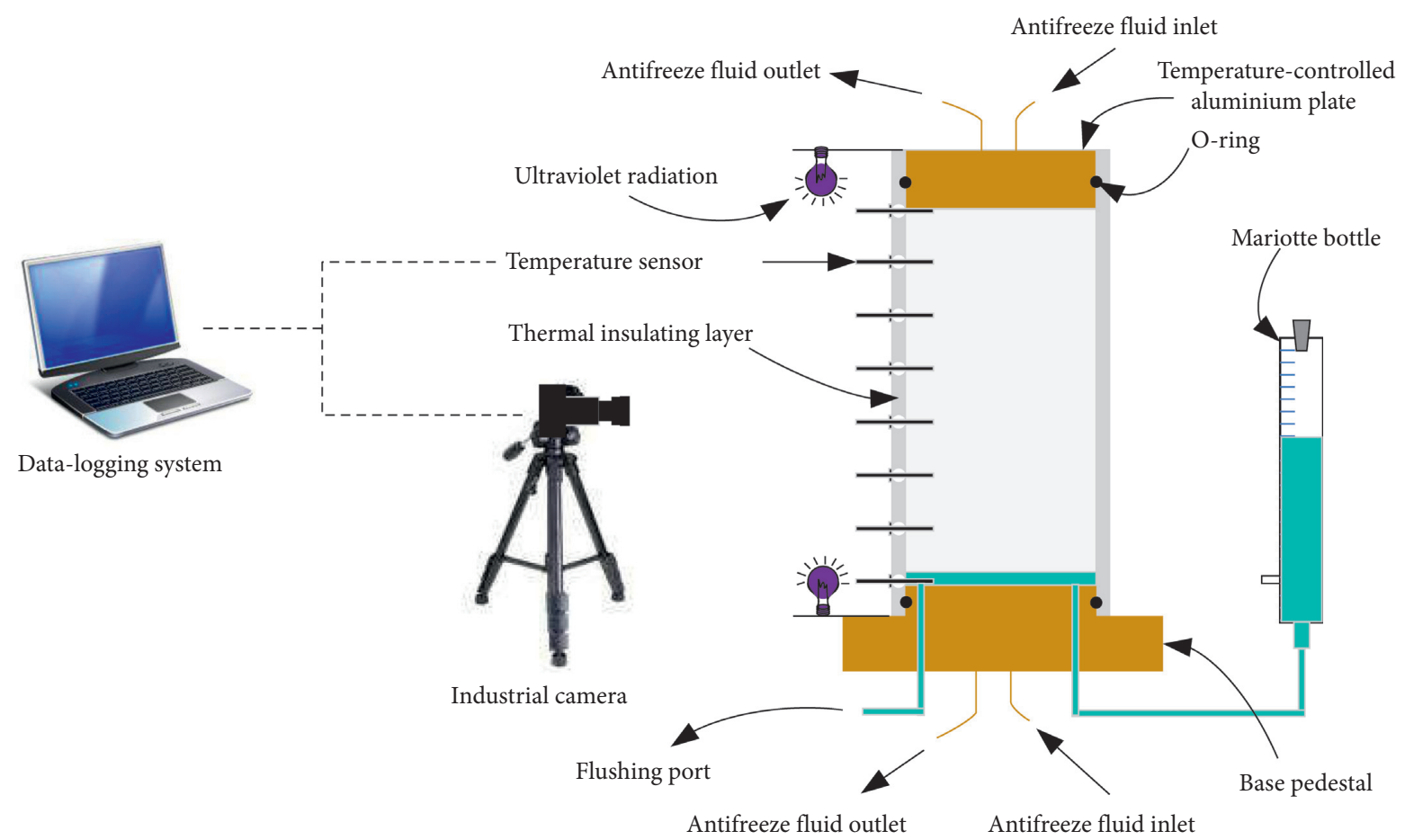

Figure 1: Liquid water-vapor migration test device.

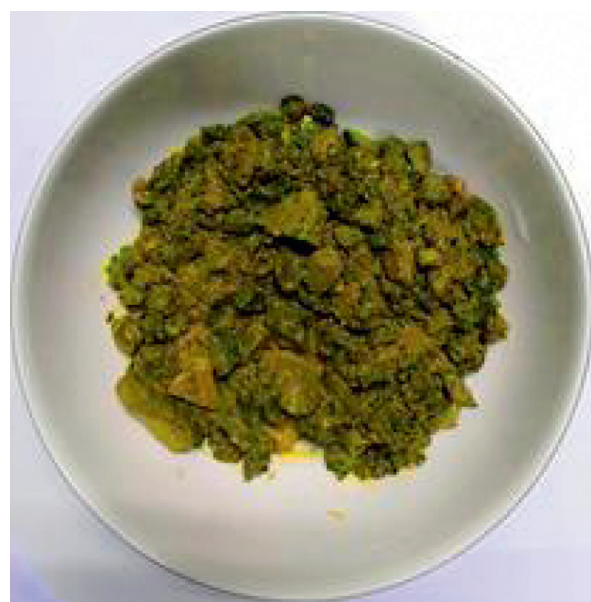

(a)

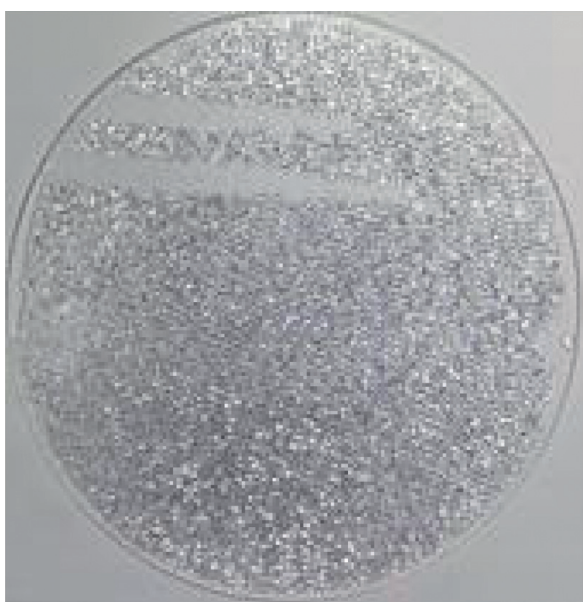

(b)

FIGURE 2: Evaporation of fluorescein in soil [26, 30, 31].

TABLe 1: Physical properties of CGS.

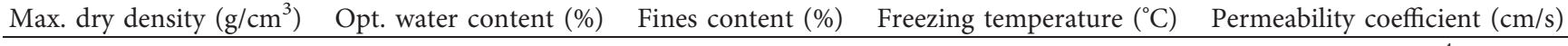
2.08 5.80 8.0 $-0.15$ $6.22 \times 10^{-4}$

"Code for Design of Railway Earth structure" (TB 10001-2016) [32], the compaction coefficient of roadbed filling should be larger than 0.92 . Therefore, soil compaction coefficients of 0.92 and 0.95 were adopted in experiments. Under open water supply and indoor freezing-thawing cycle conditions, the test scheme of different compaction levels in step cooling mode is shown in Table 2. Cooling rate in the test was set according to the calculation based on the filed monitoring data [33]. Initial water and fine particle contents were $5 \%$ and $8 \%$, respectively. Each freezing experiment lasted 72 hours, and each thawing experiment took 12 hours. The temperature of bottom cooling pedestal was fixed at $+1^{\circ} \mathrm{C}$, using step freezing mode, three levels of cooling to simulate a slow cooling winter, as shown in Figure 4. Soil samples were labeled as C1T3F3 and C2T3F3, where $\mathrm{C} 1$ and $\mathrm{C} 2$ indicated compaction coefficient of 0.92 and 0.95, respectively. T3F3 implied that the soil sample 


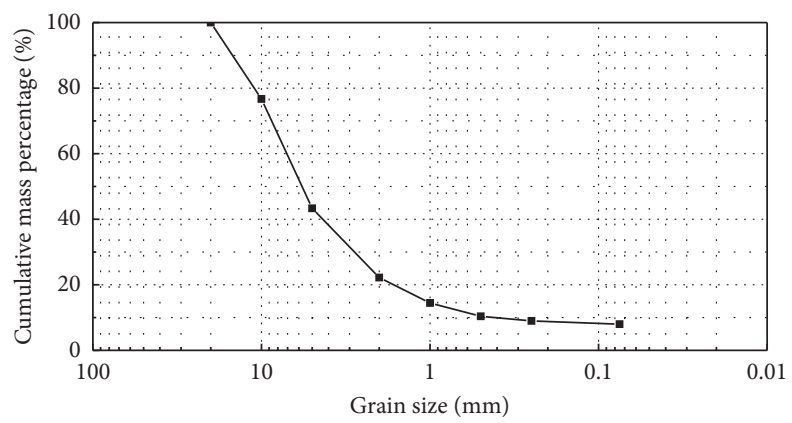

FIGURE 3: Semilog plot of particle-size distribution of CGS collected from Harbin-Qiqihar HSR subgrade.

TABLE 2: Freezing and thawing test scheme under open water supply system conditions.

\begin{tabular}{lcccc}
\hline $\begin{array}{l}\text { Experiment } \\
\text { ID }\end{array}$ & $\begin{array}{c}\text { Compaction } \\
\text { level }\end{array}$ & $\begin{array}{c}\text { Temperature of the top pedestal } \\
\text { Freezing temperature } \\
\left({ }^{\circ} \mathrm{C}\right)\end{array}$ & $\begin{array}{c}\text { Thaw temperature } \\
\left({ }^{\circ} \mathrm{C}\right)\end{array}$ & $\begin{array}{c}\text { Freezing and thawing } \\
\text { cycles }\end{array}$ \\
\hline C1T3F3 & 0.92 & $\begin{array}{c}0 \sim 24 \mathrm{~h}:-2 \\
24 \sim 48 \mathrm{~h}:-5\end{array}$ & +8 & Freezing and thawing-freezing and thawing-freezing \\
C2T3F3 & 0.95 & $48 \sim 72 \mathrm{~h}:-8$ & Freezing and thawing-freezing and thawing-freezing \\
\hline
\end{tabular}

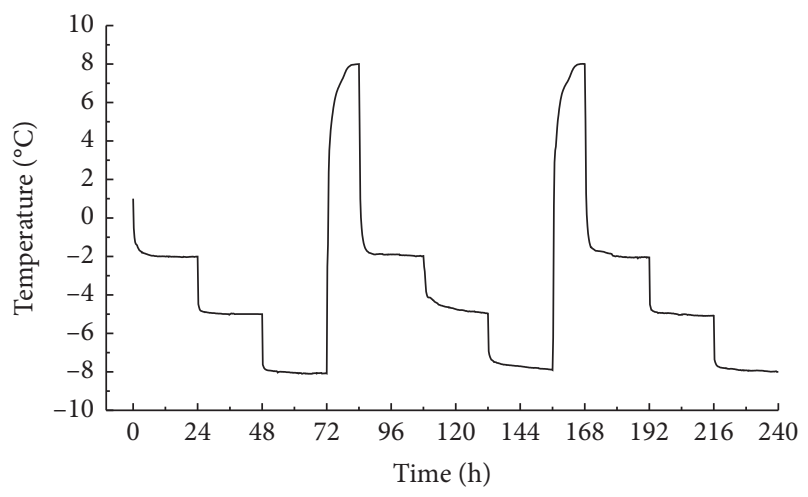

FIgURE 4: The temperature variation of the top cooling pedestal.

experienced three steps of cooling and three freezing cycles. By comparing the experimental results obtained for $\mathrm{C} 1 \mathrm{~T} 3 \mathrm{~F} 3$ and C2T3F3, the effects of compaction level on the migration characteristics of water-heat-vapor under freezing-thawing cycle were studied.

The detailed procedure was as follows:

(1) Soil samples were infiltrated with distilled water without fluorescein for 24 hours according to the moisture content determined in the test scheme to guarantee the uniformity of water content in the samples. Fluorescein and distilled water were mixed with the mass ratio of 1:200 and stirred uniformly. Then, the obtained mixture was added to a Mariotte bottle. Soil samples were placed in plexiglass cylinders and tamped in four layers. The surface of each laminated body needed to be shaved, and the top pedestal was wrapped with a plastic film to isolate it from outside air; the top pedestal was in good contact with the top of the soil samples. After loading the samples, temperature sensor was placed and wrapped with insulation cotton.
Then, the area was reserved, and images were taken using industrial camera under ultraviolet radiation.

(2) Before starting freezing-thawing cycles, the temperatures of freezing and thawing cycle test chambers were adjusted to $+1^{\circ} \mathrm{C}$ and those of top and base pedestals were set at $+1^{\circ} \mathrm{C}$ to observe the changes of internal temperature in soil samples. When the temperatures of soil samples reached $+1^{\circ} \mathrm{C}$, freezing process started; the temperature of the top pedestal was adjusted to the temperature determined in the test design. Then, fluorescein was injected into Mariotte bottle water. Mariotte bottle was used to replenish water to simulate water supply in actual projects. After freezing completed, thawing process started, and the temperature of top pedestal was directly adjusted to the thawing temperature determined in test design. During the test, temperature sensors, the water level of Mariotte bottle and the images of soil samples were recorded and stored, and the frequency was unified once every $15 \mathrm{~min}$.

(3) Periodic freezing-thawing cycles were performed in test chamber, using one-way freezing and thawing from top to bottom. The temperature of the base pedestal was fixed at $+1^{\circ} \mathrm{C}$. Tests were performed according to freezing and thawing cycles in the designed scheme. After freezing-thawing cycle finished, water replenishment was stopped, and the average layer was separated by 10 layers. The layer-wise moisture contents of soil samples were tested by the oven drying method.

\section{Results and Analysis}

3.1. Influence of Compaction Level on the Variations of Frost Penetration. The comparison of frost penetration and freezing rate during the different freezing processes of soil samples with different compaction levels is shown in Figures 5(a)-5(c), where FF is freezing front and FR 


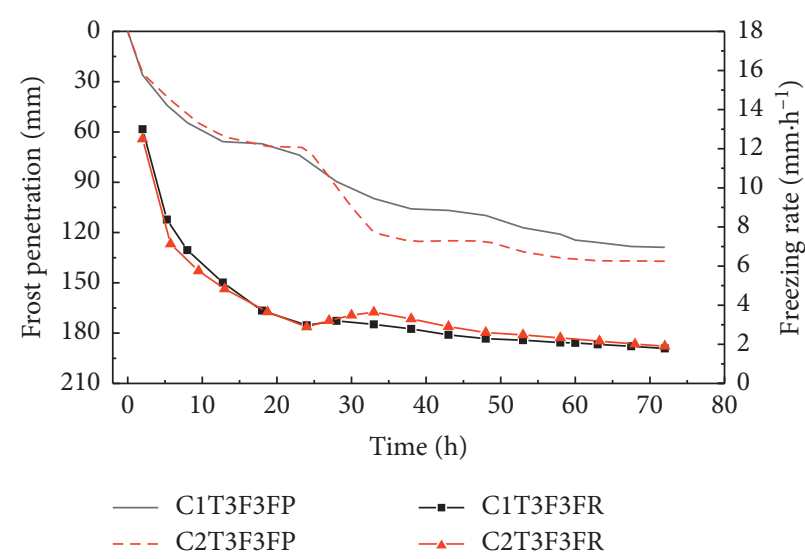

(a)

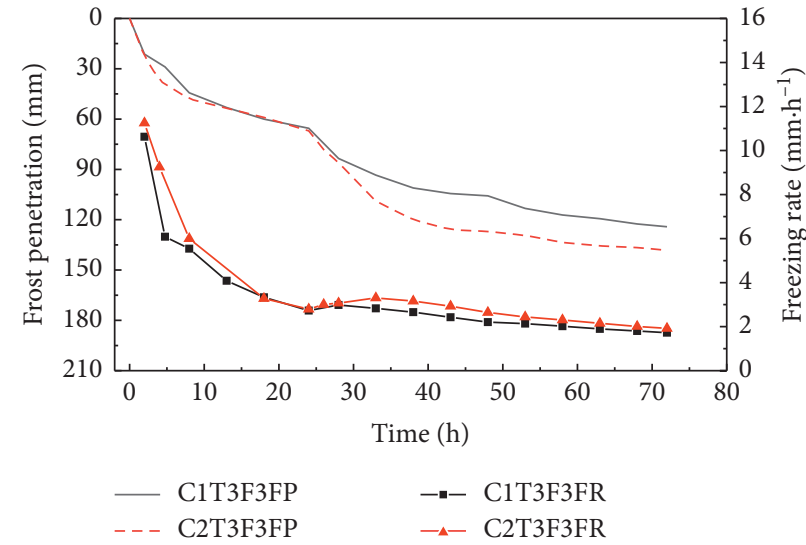

(b)

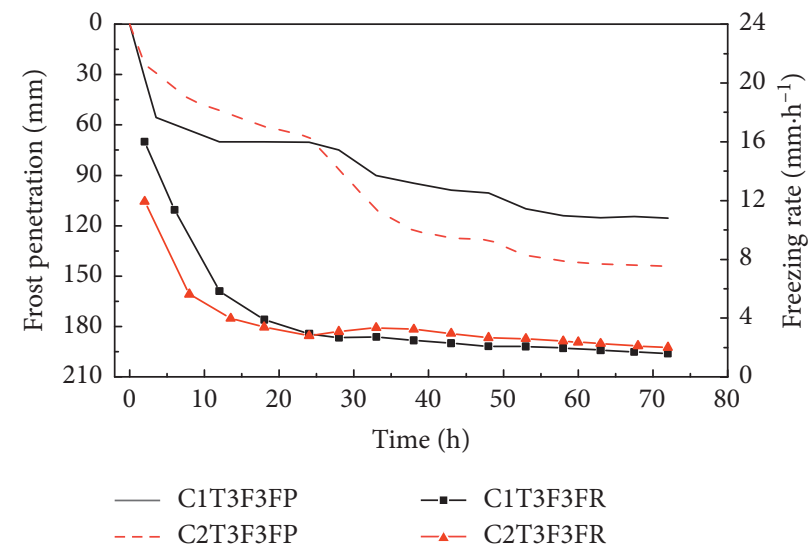

(c)

Figure 5: Variation of frost penetration and freezing rate during three freezing processes of C1T3F3 and C2T3F3 samples. (a) The first freezing. (b) The second freezing. (c) The third freezing.

represents freezing rate. The development trend of frozen front and freezing rate of the two soil samples were found to be the same. Under the conditions of the same cooling mode and temperature, greater compaction levels resulted in deeper development of frozen front and corresponding freezing rate.

\subsection{Influence of Compaction Level on Water Content and} External Water Supply. Final moisture content distribution at different compaction levels is shown in Figure 6. Crystallized ice was found at the bottom of the top pedestal in both sets of experiments [30,31]. Moisture content distribution in the frozen area showed similar trends, soil moisture content at the top of the soil samples was minimum, and the water contents of soil samples with lower compaction levels were lower than those of soil samples with higher compaction levels. In soil samples with higher compaction levels, the pores between soil particles became smaller, resulting in lower permeability coefficients; therefore, moisture migration at the top of the soil samples was less at constant temperature freezing and thawing.

Moisture content distribution in the frozen soil area was wavy, and the maximum values corresponded to the main cooling steps, as shown in Figure 6. Moisture contents in

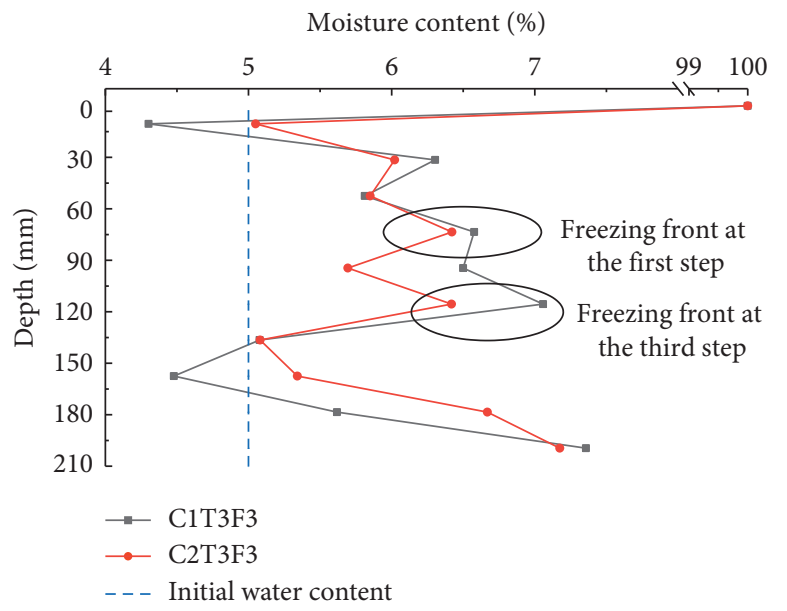

FIgURE 6: The final moisture content distributions of C1T3F3 and C2T3F3.

other areas of frozen soil were high except for top surface. This was due to the relatively low compactness of soil sample and its relatively high capillary action, which contributed to moisture migration. Conversely, permeability coefficient reduced for soil samples with higher compaction levels 
where freezing rate developed more rapidly; therefore, the moisture contents of soil samples with high compaction levels were lower in frozen areas and were increased in unfrozen areas. They were also smaller than those of soil samples with less compaction.

The bottom of soil samples was connected to Mariotte bottle, and the amount of water was calculated by observing water level scale in the Mariotte bottle. During freezing process, water level in Mariotte bottle showed a downward trend indicating that moisture migrated from Mariotte bottle to soil sample. When freezing completed, the temperature of the top pedestal was increased for thawing. Water level in Mariotte bottle showed an upward trend during thawing process, indicating that the moisture inside the soil samples migrated into the Mariotte bottle. Under the action of self-weight, unfrozen water migrated to the warm end of soil samples, which was opposite to water migration direction during freezing process. The changing trend of the amount of moisture supply during each freezing process and water discharge during each thawing process were gradually increased with almost similar trends, and increasing rate gradually decreased.

The comparison of water replenishment for two different compaction soil samples under different freezing times is shown in Figures $7(\mathrm{a})-7(\mathrm{c})$. The variations of moisture supply and discharge during two thawing processes are shown in Figures $7(\mathrm{~d})$ and $7(\mathrm{e})$. It was observed from Figure 6 that water level in Mariotte bottle did not start to change at the beginning of temperature rise step or decrease during the first freezing-thawing cycle, but started after a period of time. As shown in Figures $7(\mathrm{a})$ and $7(\mathrm{~d})$, the temperature of the top pedestal was changed from positive to negative during the second and third freezing processes, and initial freezing stage had a short moisture discharge process. As the temperature of the top pedestal continued to decrease, the freezing front gradually moved from cold end to warm end, which led to the moisture in the unfrozen area migrating to the freezing front under the temperature gradient. Initial water supply time of the two soil samples was relatively close to each other except for the first freezing process. During the first and second freezing processes, by decreasing compaction level, initial water replenishment time accelerated. It was observed that higher compaction levels resulted in relatively small pores between soils particles and permeability coefficient decreased which was not conducive to external water migration.

3.3. Influence of Compaction Level on the Migration Height of Liquid Water. The variation of the $\mathrm{C} 2 \mathrm{~T} 3 \mathrm{~F} 3$ migration height of liquid water traced by fluorescein is shown in Figure 8. It can be seen from Figure 8(a) that, during the first freezing process, C2T3F3 did not have fluorescein at the bottom of soil sample during 0 to $34.0 \mathrm{~h}$ of testing time. Once water supply began at $34.0 \mathrm{~h}$, fluorescein was found at the bottom of soil sample. Between 34.0 and $60.0 \mathrm{~h}$, liquid water migration height continued to increase and external water migrated to the bottom of soil sample in a mixed form of liquid water-vapor. No variation was observed in the migration height of liquid water between 60.0 and $72.0 \mathrm{~h}$. Figure 8(a) shows that the water level of Mariotte bottle continuously decreased during this period, which indicated that external water migrated to the bottom of soil sample, first in a mixed form together with the original moisture and then, in vapor form. After moving to the top of the soil sample, liquid water reached equilibrium state under its own weight and matrix suction.

During the first thawing process, liquid water migration height did not change between 72.0 and $76.0 \mathrm{~h}$. At this stage, the internal moisture of soil sample did not migrate to outside. At $76.0 \mathrm{~h}$, liquid water migration height began to decrease, and the moisture inside soil sample began to migrate to outside, which was close to initial water discharge time. The migration height of liquid water continued to decrease between 76.0 and $79.8 \mathrm{~h}$, indicating that the water inside the soil sample continued to migrate to the outside. Fluorescein at the bottom of soil sample almost disappeared from 79.8 to $84.0 \mathrm{~h}$, indicating that the amount of external liquid water migrated from the outside to the bottom of the soil sample decreased gradually. The variation of liquid water migration during second and third freezing processes was similar to that during the first freezing. It was also found that the second thawing process was almost similar to the first thawing process with slight differences only at the beginning of water supply or discharge step and stable liquid water migration period.

The comparison of the variations of the liquid water migration heights of $\mathrm{C} 1 \mathrm{~T} 3 \mathrm{~F} 3$ and $\mathrm{C} 2 \mathrm{~T} 3 \mathrm{~F} 3$ with different compaction levels in time is shown in Figure 8(c). The variations of liquid water migration height among the two soil samples during freezing and thawing cycles were similar. During the freezing process, starting from initial water supply step, external water migrated to the bottom of soil sample in a mixed form, increasing liquid water migration height. After an increasing step, liquid water migration was highly stable, and external water continued to migrate to the bottom of the soil sample in the mixed form of liquid water and vapor. Then, together with original moisture at the position, it mainly migrated to the upper part of soil sample in the form of vapor, and then external liquid water was replenished. Equilibrium was achieved under the action of its own weight and matrix suction. During the thawing process, liquid water migration height decreased from initial water discharge time, because under the action of gravity, the moisture in the upper part of soil sample migrated to the outside, gradually decreasing moisture content inside the soil sample.

It was observed that the liquid water migration height of C2T3F3 gradually increased with the increase of freezing numbers and was finally increased by $2.3 \mathrm{~cm}$ after the completion of experiments. The migration height of liquid water in C1T3F3 did not increase with the increase of the number of freezing cycles, and final migration height was close to that after the first freezing, which was $1.5 \mathrm{~cm}$. At the same time, liquid water migration height during the thawing process of the compact soil sample C2T3F3 was more obvious, and it was estimated that the increase of compaction level contributed to the upward migration and downward discharge of liquid water. 


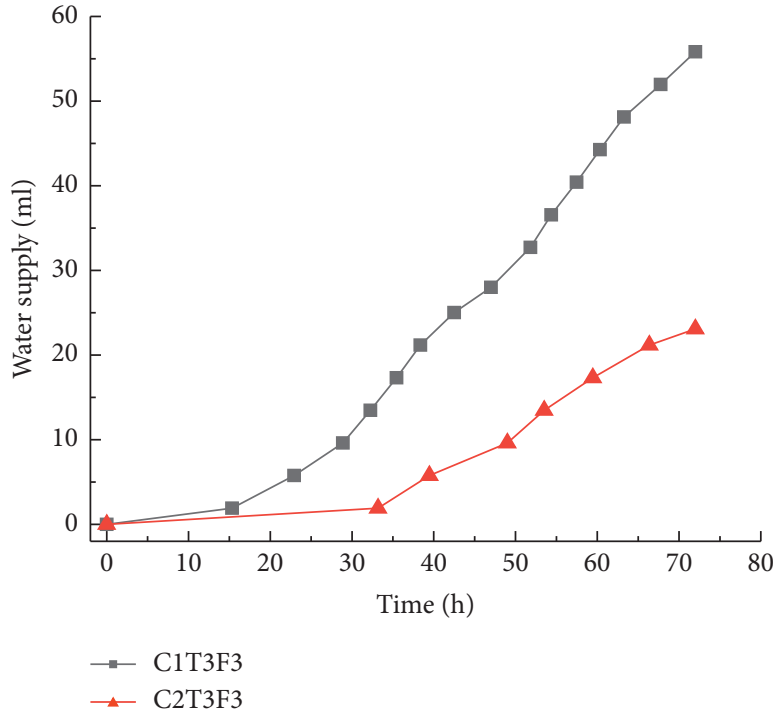

(a)

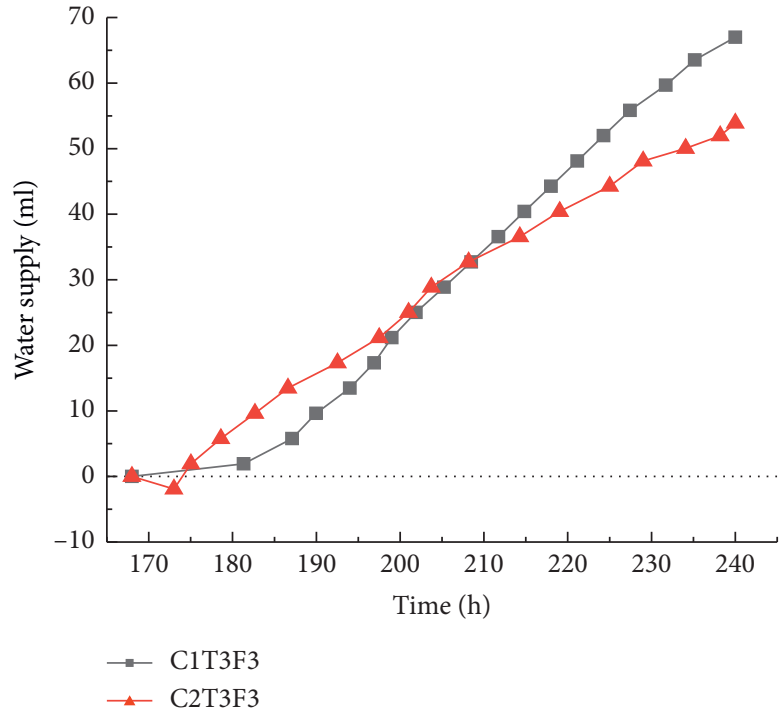

(c)

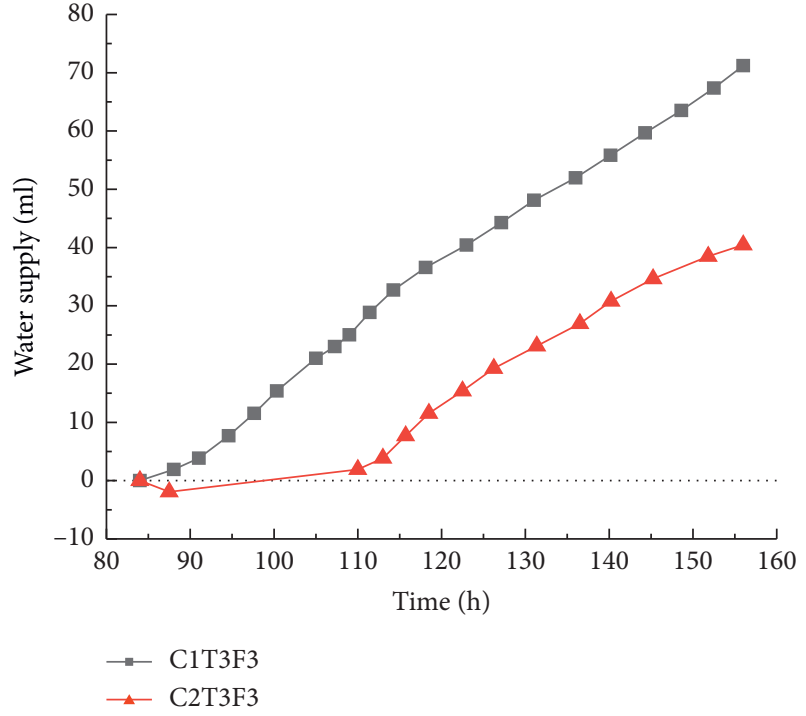

(b)

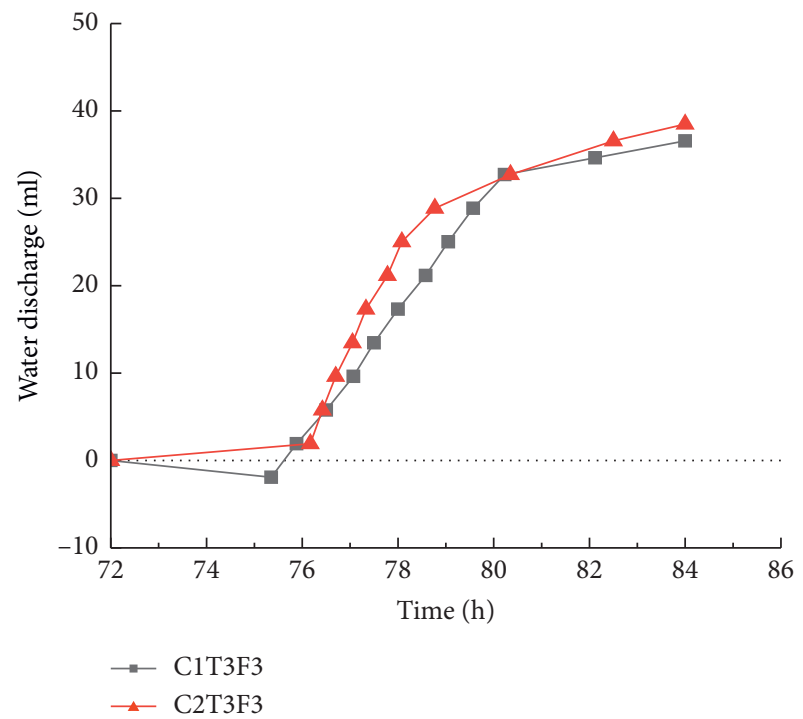

(d)

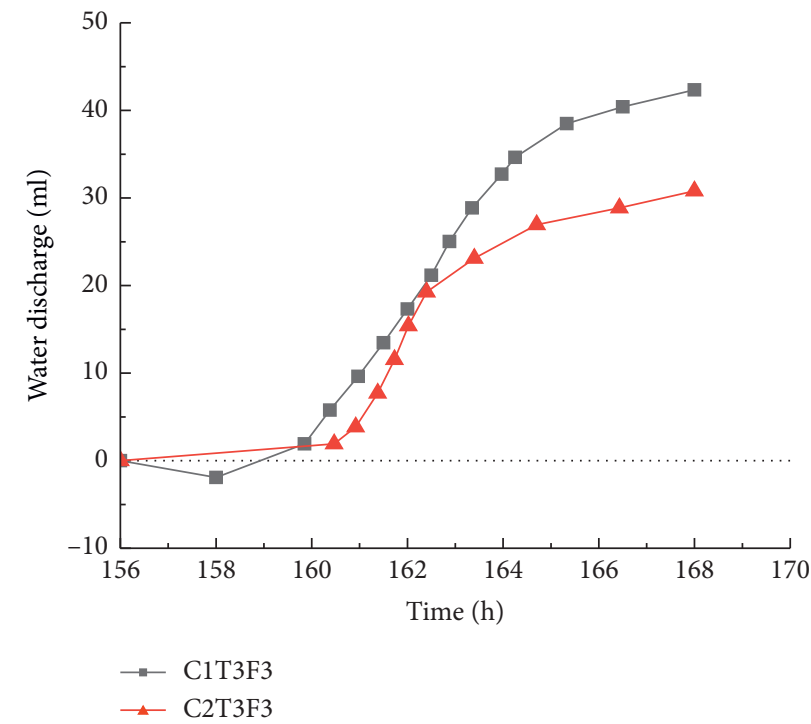

(e)

Figure 7: Comparison of water supply and discharge with different compaction levels. (a) First freezing. (b) Second freezing. (c) Third freezing. (d) First thawing. (e) Second thawing. 


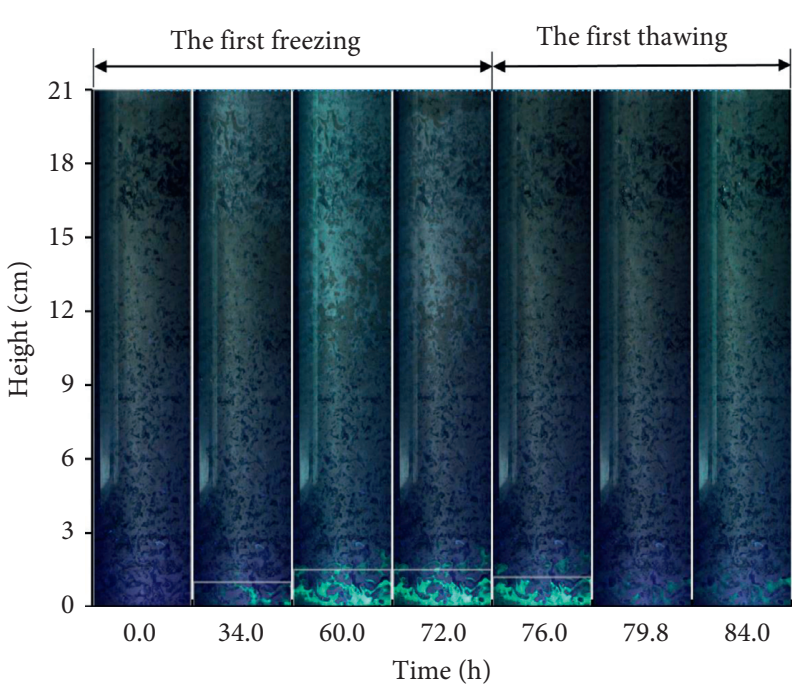

(a)

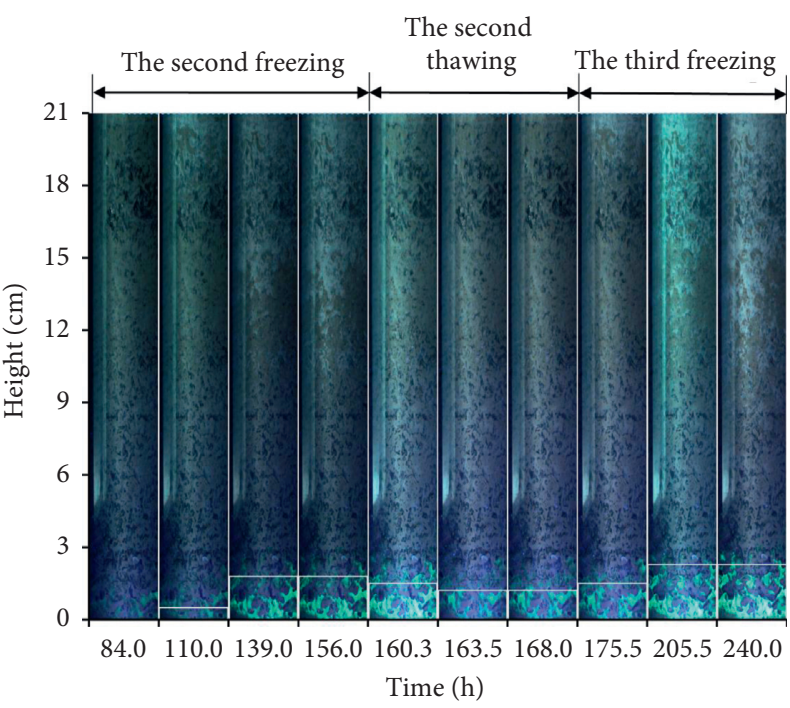

(b)

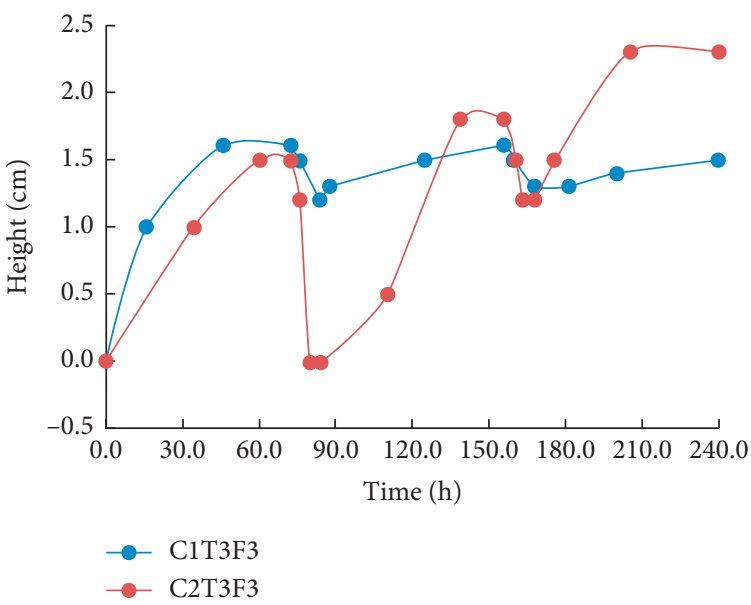

(c)

FIGURE 8: Variation of the migration height traced by fluorescein during the freezing and thawing test. (a) Liquid water height change during the first freezing and thawing. (b) Liquid water height change during the second freezing, second thawing, and third freezing. (c) Liquid water migration height changes during the freezing and thawing cycles of C1T3F3 and C2T3F3.

\subsection{Comparison of the Influence of Compaction Level on CGS} Characteristics of Water-Heat-Vapor. With the same number of freezing processes, higher compaction levels led to greater depths of frost penetration. Also, with the same water content, higher compaction levels increased the amount of soil particles per unit volume of soil sample, the porosity then decreased, and the thermal conductivity of the soil particles was greater than the thermal conductivity of gas phase filler; the thermal conductivity increased with the increase of the compaction level. Therefore, it was found through experiment that the development of frozen front was relatively deeper at higher compaction levels. Under the same compaction levels and freezing conditions, higher numbers of freezing-thawing cycles resulted in greater frost penetration. Zhang et al. also found that increasing the number of freezing-thawing cycles increased CGS frost penetration [26]. According to the experimental results obtained in this work, increasing the number of freezing- thawing cycles further increased the compaction level and then frost penetration. An increase in the number of freezing-thawing cycles made soil samples with less compaction denser and vice versa [34]. However, the obtained results suggested that, after a certain number of freezingthawing cycles, the compactness of soil samples gradually stabilized [34].

The increase of compaction level decreased water supply during freezing, especially during the first two freezing processes. For the two soil samples with different compaction levels, water content distribution in frozen soil area was wavy and the number of maximum value corresponded to the number of cooling times. Among them, water content at the top of the soil sample was minimum within the height range of the soil sample, and the water content of soil sample with the smaller compaction level was lower. As the number of freezing-thawing cycles increased, water content at the top of soil samples decreased significantly. It was observed that 
the increase of compaction level decreased the porosity of soil samples, which was not conducive to the migration of external water [34]. However, the reduction of compaction level increased liquid water-vapor migration, especially at the top.

By comparing the migration heights of liquid water under two compaction levels, it was observed that the change of liquid water migration height had the same characteristics. External liquid water inside soil sample had a very limited migration height under the actions of gravity and matrix suction. Moisture redistribution mainly occurred due to vapor migration. The migration heights of liquid water were different. As the number of freezing increased, the migration height of liquid water in samples with high compaction levels increased gradually, while that in samples with low compaction levels did not change. After three freezing processes, the liquid water migration height of soil samples with high compaction levels was about $0.8 \mathrm{~cm}$ higher than that with lower compaction levels. During the two thawing processes, liquid water migration was more pronounced in samples with higher compaction levels. Therefore, an increase in compaction level could be beneficial to the migration of liquid water in the lower part of soil samples.

From the above experiments, it could be concluded that although frost penetration was slightly larger, compaction level increase during construction reduced the liquid watervapor migration during freezing process and upward migration of top moisture reducing frost heave deformation in subgrade. The increase of freezing-thawing cycles probably increased the compaction level of CGS. The increase of compaction level can be beneficial to the migration of liquid water. Accordingly, since the total amount of liquid watervapor migration reduced at this time, the amount of vapor migration decreased correspondingly. Therefore, in engineering practices, filling compaction should be as sufficient and uniform as possible to avoid the change of water-heatvapor effect due to uneven compaction level, which led to uneven deformation of roadbed fillings and uneven change of mechanical properties, creating roadbed problems.

\section{Conclusion}

The same freezing-thawing test was performed on two soil samples with different compaction levels to study water-heatvapor characteristics and the influence of compaction level under freezing-thawing cycles. By analyzing the temperature, layered moisture content, external water replenishment, and image tracing of soil samples, it was concluded that the change of compaction level changed CGS water-heat-vapor characteristics. The following conclusions were drawn:

(i) During the freezing processes, the outside water migrated to the inside of soil sample and during thawing processes; the water inside the soil sample migrated to the outside. The internal water migration of soil samples was dominated by vapor migration.

(ii) With the increase of compaction level, frost penetration and corresponding freezing rate increased.
When compaction level increased, initial water supply time delayed, the amount of water replenishment reduced, and the vapor content of the top of the soil sample moving up to top cold pedestal also decreased.

(iii) With the increase of compaction level, the migration height of liquid water increased. The increase of compaction level also increased liquid water migration and reduced vapor migration.

Future research can focus on the following topics:

(i) The effect of freezing-thawing cycles on the deformation and mechanical properties of CGS with different compaction levels

(ii) The relationship between the characteristics of water-heat-vapor and CGS deformation, as well as mechanical properties under the action of freezingthawing cycles.

\section{Data Availability}

All data used to support the findings of this study are available from the corresponding author upon request.

\section{Conflicts of Interest}

The authors declare that they have no conflicts of interest in connection with the work submitted.

\section{Acknowledgments}

This work was funded by the National Natural Science Foundation of China (NSFC) under Grant nos. 51708369 and 51978426, the National Key Research and Development Program of Ministry of Science and Technology under Grant nos. 2019YFC1509604-02, the Natural Science Foundation of Hebei Province under Grant no. E2017210110, Open Project of State Key Laboratory of Frozen Soils Engineering under Grant no. SKLFSE201711, the Science Foundation of Chinese Post-Doctoral under Grant no. 2018M633607, and Key Research Project of Science and Technology Department of Sichuan Province under Grant no. 2018GZ0050.

\section{References}

[1] J. Kodikara, T. Islam, and A. Sounthararajah, "Review of soil compaction: history and recent developments," Transportation Geotechnics, vol. 17, pp. 24-34, 2018.

[2] L. J. Ebels, R. Lorio, and C. van der Merwe, "The importance of compaction from an historical perspective," in Proceedings of the 23rd Southern African Transport Conference (SATC 2004), Pretoria, South Africa, July 2004.

[3] X. Zhu, S. Bai, G. Xue et al., "Assessment of compaction quality of multi-layer pavement structure based on intelligent compaction technology," Construction and Building Materials, vol. 161, pp. 316-329, 2018.

[4] J. Chen, E. E. Alonso, C. Gu, Z. Cao, and Y. Cai, "Long term cyclic behavior of unsaturated granular soils," Transportation Geotechnics, vol. 17, pp. 48-55, 2018. 
[5] E. L. Matyas and H. S. Radhakrishna, "Volume change characteristics of partially saturated soils," Géotechnique, vol. 18, no. 4, pp. 432-448, 1968.

[6] J. Kodikara, "New framework for volumetric constitutive behaviour of compacted unsaturated soils," Canadian Geotechnical Journal, vol. 49, no. 11, pp. 1227-1243, 2012.

[7] Z. Zhou, W. Ma, S. Zhang, H. Du, Y. Mu, and G. Li, "Multiaxial creep of frozen loess," Mechanics of Materials, vol. 95, pp. 172-191, 2016.

[8] X. T. Xu, W. D. Zhang, C. X. Fan, Y. Lai, and J. Wu, "Effect of freeze-thaw cycles on the accumulative deformation of frozen clay under cyclic loading conditions: experimental evidence and theoretical model," Road Materials and Pavement Design, 2019.

[9] Z. Lu, S. Xian, H. Yao, R. Fang, and J. She, "Influence of freezethaw cycles in the presence of a supplementary water supply on mechanical properties of compacted soil," Cold Regions Science and Technology, vol. 157, pp. 42-52, 2019.

[10] T. Ishikawa, Y. Zhang, T. Tokoro, and S. Miura, "Medium-size triaxial apparatus for unsaturated granular subbase course materials," Soils and Foundations, vol. 54, no. 1, pp. 67-80, 2014.

[11] A. Cetin, Z. Kaya, B. Cetin, and A. H. Aydilek, "Influence of laboratory compaction method on mechanical and hydraulic characteristics of unbound granular base materials," Road Materials and Pavement Design, vol. 15, no. 1, pp. 220-235, 2014.

[12] D. Sheng, "Review of fundamental principles in modelling unsaturated soil behaviour," Computers and Geotechnics, vol. 38, no. 6, pp. 757-776, 2011.

[13] G. J. Bouyoucos, "Effect of temperature on the movement of water vapor and capillary moisture in soils," Journal of Agricultural Research, vol. 5, no. 4, pp. 141-172, 1915.

[14] W. O. Smith, "Thermal conductivities in moist soils," Soil Science Society of America Journal, vol. 4, no. C, pp. 32-40, 1940.

[15] W. O. Smith, "Thermal transfer of moisture in soils," Transactions, American Geophysical Union, vol. 24, no. 2, pp. 511-524, 1943.

[16] C. G. Gurr, T. J. Marshall, and J. T. Hutton, "Movement of water in soil due to a temperature gradient," Soil Science, vol. 74, no. 2, pp. 335-345, 1952.

[17] G. T. Zhao, J. Y. Jiang, Y. H. Cui et al., "Distribution features of fine-grain in filling materials of high-speed railway subgrade and impact on frost heaving," Journal of The China Railway Society, vol. 39, no. 10, pp. 1-9, 2017.

[18] J. D. Teng, Z. Y. He, S. Zhang et al., "Moisture transfer and phase change in unsaturated soils: physical mechanism and numerical model for two types of canopy effect," Chinese Journal of Geotechnical Engineering, vol. 38, no. 10, pp. 1813-1821, 2016.

[19] S. Zhang, Z. Y. He, J. D. Teng et al., "Water vapor transfer and phase change in unsaturated soils: experimental study on two types of canopy effect," Chinese Journal of Geotechnical Engineering, vol. 39, no. 5, pp. 961-968, 2017, (in Chinese).

[20] Y. Yang and W. G. Zhao, "Curvelet transform-based identification of void diseases in ballastless track by groundpenetrating radar," Structural Control \& Health Monitoring, vol. 26, no. 4, pp. 1-18, 2019.

[21] S. Zhang, J. Teng, Z. He et al., "Canopy effect caused by vapour transfer in covered freezing soils," Géotechnique, vol. 66, no. 11, pp. 927-940, 2016.
[22] J. Teng, F. Shan, Z. He, S. Zhang, G. Zhao, and D. Sheng, "Experimental study of ice accumulation in unsaturated clean sand," Géotechnique, vol. 69, no. 3, pp. 251-259, 2019.

[23] Z. Y. He, J. D. Teng, S. Zhang, and D. C. Sheng, "Moisture transfer and phase change in unsaturated soils: an experimental study of two types of canopy effect," Sciences in Cold and Arid Regions, vol. 3, no. 3, pp. 243-249, 2017.

[24] J. Gao, Y. Lai, M. zhang, and Z. Feng, "Experimental study on the water-heat-vapor behavior in a freezing coarse-grained soil," Applied Thermal Engineering, vol. 128, pp. 956-965, 2018.

[25] R. Bai, Y. Lai, M. Zhang, and J. Gao, "Water-vapor-heat behavior in a freezing unsaturated coarse-grained soil with a closed top," Cold Regions Science and Technology, vol. 155, pp. 120-126, 2018.

[26] Y.-z. Zhang, W. Ma, T.-1. Wang, B.-y. Cheng, and A. Wen, "Characteristics of the liquid and vapor migration of coarsegrained soil in an open-system under constant-temperature freezing," Cold Regions Science and Technology, vol. 165, p. 102793, 2019.

[27] T.-1. Wang, Y.-z. Zhang, M. Wei, B.-y. Cheng, and A. Wen, "Investigation of liquid and vapor migration in coarse-grained soil during open-system step-freezing test," Cold Regions Science and Technology, vol. 165, p. 102816, 2019.

[28] L. U. Arenson and D. C. Sego, "The effect of salinity on the freezing of coarse-grained sands," Canadian Geotechnical Journal, vol. 43, no. 3, pp. 325-337, 2006.

[29] O. Iwakun, K. Biggar, and D. Sego, "Influence of cyclic freezethaw on the mobilization of LNAPL and soluble oil in a porous media," Cold Regions Science and Technology, vol. 64, no. 1, pp. 9-18, 2010.

[30] Y. Z. Zhang, W. Ma, W. G. Zhao, P. Li, and B. X. Wang, "Water-heat-vapor migration trace and characteristics of unsaturated coarse-grained filling under freeze and thaw cycles," Chinese Journal of Rock Mechanics and Engineering, vol. 39, no. 1, pp. 156-165, 2020, (in Chinese).

[31] Y. Zhang, W. Zhao, W. Ma, H. Wang, A. Wen, and P. Li, "Effect of different freezing modes on the water-heat-vapor behavior in unsaturated coarse-grained filling exposed to freezing and thawing," Cold Regions Science and Technology, vol. 174, p. 103038, 2020.

[32] China State Railway Administration (CSRA, Code for Design of Railway Earth Structure (TB 10001-2016), China Railway Publishing House, Beijing, China, 2017.

[33] Y. Z. Zhang, B. C. Sun, P. Li, X. J. Liang, and J. Yang, "Analysis of deformation and temperature characteristics of high-speed railway roadbed in seasonal frozen regions," Soil Mechanics and Foundation Engineering, 2020, In press.

[34] T.-l. Wang, Y.-j. Liu, H. Yan, and L. Xu, "An experimental study on the mechanical properties of silty soils under repeated freeze-thaw cycles," Cold Regions Science and Technology, vol. 112, pp. 51-65, 2015. 